that organisms used only $a$-amino acids to build their proteins. But Michael Ibba at Ohio State University in Columbus and his team have found that Salmonella make the structurally different $\beta$ version of the amino acid lysine. In the bacteria, an enzyme called PoxA binds to $\beta$-lysine and passes it to the protein EF-P, which functions as a transferRNA mimic during protein synthesis. The researchers show that EF-P, a protein essential to Salmonella's virulence, is active only when it contains $\beta$-lysine.

Ibba's team think that the $\beta$-lysine-incorporation pathway could represent a new target for effective antibiotics against Salmonella.

Nature Chem. Biol. http://dx.doi. org/10.1038/nchembio.632 (2011)

\section{GEOLOGY}

\section{Rivers and trees evolve together}

River systems around the world diversified during the Palaeozoic era, 542 million to 251 million years ago. Before this, most rivers were shallow and wide; afterwards, some featured deep, branching channels and stable islands.

Neil Davies and Martin Gibling at Dalhousie University in Halifax, Canada, reviewed literature and visited sites of sedimentary-rock formations to determine more precisely when the change occurred. They argue for the Carboniferous period, 359 million to 299 million years ago, when the rise of trees created tough root systems able to stabilize river banks and woody debris that could block rivers and promote branching. Nature Geosci. http://dx.doi. org/10.1038/ngeo1237 (2011)

\section{CANCER}

\section{Beyond the bullseye}

Cancer drugs that target specific proteins overproduced because of a genetic abnormality may also be effective in patients whose tumours lack that abnormality.

Jeff Settleman at Genentech in South San Francisco, California, and his team found a molecular marker in some cancers that could pinpoint patients likely to respond to drugs targeting HER $2-a$ protein overexpressed in about $25 \%$ of breast cancers - even though the HER2 gene in their tumours functions normally.

The researchers identified a number of such tumours, many of them head and neck cancers, in a screen of 690 tumour cell lines. Further experiments found that these tumours are driven by a boost in the protein neuregulin-1, which activates HER2 indirectly by switching on its sister protein, HER3. The HER2 inhibitor lapatinib disrupted the pathway in vitro, and suppressed HER2, HER3 and tumour growth in a human cancer cell line engrafted into mice.

Cancer Cell 20, 158-172 (2011)

PHYSICS
Switching up
spin

'Spintronic' devices compute with the magnetic orientation of tiny nanomagnets. They could potentially be more energy efficient than conventional charge-based electronics, but only if scientists can find a way to 'switch' the magnetic bits with minimal loss of energy.

Kuntal Roy and his colleagues at Virginia Commonwealth University in Richmond have developed an idea for a low-energy nanomagnetic switch. It comprises a thin magnetic layer deposited on a piezoelectric material - one that deforms in the presence of charge. When small voltages are applied to the piezoelectric, it deforms and strains the thin magnetic layer, causing its magnetization to change direction and flip the bit. Such a switch could be so efficient that it could run on ambient energy harvested from the environment.

Appl. Phys. Lett. 99, 063108 (2011)

COMMUNITY CHOICE

The most viewed papers in science

MOLECULAR BIOLOGY

\title{
RNA's secret language
}

\section{HIGHLY READ \\ on www.cell.com \\ 20 Jul-19 Aug}

Different types of RNA molecule can communicate with one another through RNA sequences called microRNA response elements (MREs).

The classical vision of RNA - as merely an intermediate between DNA and proteins - has been overturned by the discovery of many types of RNA that have functions other than protein-coding. One class of non-coding RNAs, the microRNAs, inhibits gene expression by binding to MREs and decreasing the stability of protein-coding messenger RNAs or limiting their translation into proteins.

But in an overview of recently published results, Pier Paolo Pandolfi of the Beth Israel Deaconess Cancer Center in Boston, Massachusetts, and his colleagues propose that coding and non-coding RNAs can compete for binding to microRNAs. This provides a mechanism by which MREs mediate communication, allowing different forms of RNA to 'talk' to each other and build large regulatory networks. Cell 146, 353-358 (2011)

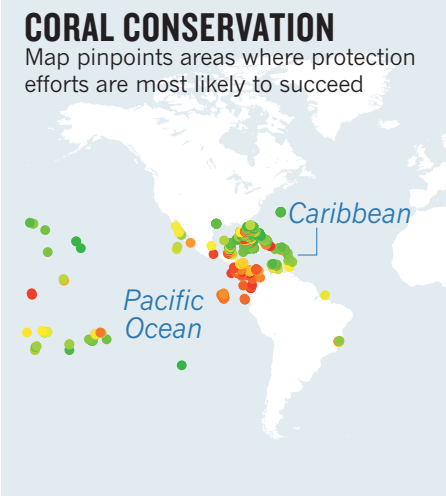

\section{Mapping reef stress}

Coral reefs are declining worldwide as a result of environmental pressures such as high temperatures, ultraviolet radiation and nutrient pollution.

Joseph Maina at Macquarie University in Sydney, Australia, and his colleagues mapped and quantified the exposure of coral to these stressors and associated factors around the world. They grouped coral regions into two clusters (pictured). One is typically exposed to high stress, with
Moderate to severe stress, with stress-reducing factors Severe stress, no stressreducing factors

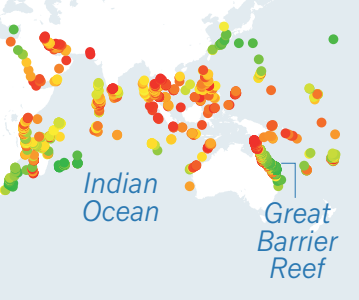

mitigating factors such as temperature variability or large tidal amplitude, and includes the central Indian Ocean. The other includes regions such as the Great Barrier Reef, and has moderate-to-high stress exposure, but also benefits from stress-reducing features.

The team says that the results could help to focus conservation efforts on regions where they are most likely to succeed, and to design effective management strategies.

PLoS One 6, e23064 (2011)

\section{$\rightarrow$ NATURE.COM}

For the latest research published by Naturevisit:

www.nature.com/latestresearch 